Motrivivência v. 26, n. 43, p. 198-211, dezembro/2014

http://dx.doi.org/10.5007/2175-8042.2014v26n43p198

\title{
FOTOGRAFIA NA ERA DIGITAL: produção, protagonismo e performance - problemas para a Educação Física/Ciências do Esporte
}

Fernando Gonçalves Bitencourt ${ }^{1}$

\section{RESUMO}

Este texto, fruto das observações oriundas de "micro" etnografias realizadas durante estágio de doutorado em Madri, reflete sobre a fotografia, tomada por agentes sociais distintos, de desportistas e espaços desportivos na era digital. Considerando a profusão de imagens e a facilidade de difusão via internet, questiona implicações ético-morais da captura destas e os sentidos da produção, protagonismo e performances. Sugiro haver 'gosto de classe' e 'habitus' a orientar estas práticas. A apropriação da imagem alheia (de ídolos e anônimos) e a exacerbação do individualismo caracterizam este 'ethos', cujo perigo reside no uso privado e na publicização inconsequente da vida alheia.

Palavras-chave: Educação Física/Ciências do Esporte; Mídia; Fotografia; Ética

1 Doutor em Antropologia Social. Docente de Educação Física do IFSC/Campus São José. São José/Santa Catarina, Brasil.

E-mail: ferbit@ifsc.edu.br 


\section{Abrindo o Obturador}

O trabalho como pesquisador sobre os meios de comunicação tem nos obrigado a refletir sobre os inúmeros problemas que a "sociedade do espetáculo" (DEBORD, 1997) suscita no âmbito da Educação Física/ Ciências do Esporte. A "Indústria Cultural" (ADORNO \& HORKHEIMER, 1985) e o tema de sua estrutura, os modos de recepção das mensagens, a produção do discurso midiático - imagem-texto, os usos das TICs na educação (física), as metodologias de pesquisa e análise representam alguns destes problemas. Este texto, por sua vez, é fruto de diálogos em diferentes instâncias, de insights de vários pesquisadores e, ainda, fruto da experiência que a tecnologia digital, especificamente da máquina fotográfica, me proporcionou durante meu estágio de doutoramento no exterior ${ }^{2}$.

Por um lado, uma palestra preferida pelo professor italiano Pier Cesare Rivoltella (especialista em Mídia e Educação da Universidade Católica de Milão) durante sua visita ao CED/UFSC no primeiro semestre de 2008, alertou para o problema da produção das imagens e sua divulgação na internet. Vídeos feitos por estudantes, mostrando alunos sendo surrados, professores mal tratados e outras espécies de bizarrices pululam nos sites especializados e tem sua gênese no ambiente escolar ${ }^{3}$. O efeito, no plano da pesquisa, é o de provocar questionamentos aos pesquisadores e educadores não apenas quanto ao plano da recepção, mas também da produção de imagens.

Na mesma perspectiva, pesquisas realizadas no âmbito da relação educação física, esporte e mídia mergulham, já há algum tempo, na complexidade do fenômeno: o trabalho de Oliveira (2005a; 2005b) que levou a filmadora para a escola e refletiu, juntamente com os alunos investigados, sobre as possibilidades abertas pela captura, decupagem e edição de imagens soma-se ao de Mendes (2008a; 2008b), que movimentou professores e alunos na direção do conhecimento técnico e crítico reflexivo sobre a mídia a partir do trabalho com vídeo na escola. Mais recentemente, Bianchi (2009) realizou estudos com a criação de blogs por alunos e professores da escola pública. Em todos estes casos, aprender sobre a mídia estava no cerne da questão, tendo sempre no horizonte, como imposição mesmo de quem trabalha com educação, as implicações éticas desta produção.

De minha parte - junto a outros pesquisadores - (BITENCOURT, 2005a; 2005b), tenho tentado pensar a mídia a partir de sua estrutura, refletindo sobre as possibilidades de, no interior do campo midiático, produzir um discurso crítico sobre o humano, em geral, e sobre a educação física e o esporte, em particular. Mas o tema desta investigação surge de uma banalidade: a compra ou não de uma máquina fotográfica. A aquisição do equipamento teve como efeito uma modificação de minha relação

2 Agradeço a CAPES a concessão de uma bolsa para a realização deste estágio.

3 Claro que, por princípio, já está posto o problema da violência física ou moral contra as pessoas. Mas há, em vários casos, talvez como um agravante, a premeditação da imagem como suporte para tal violência. Ou seja, o bater está associado à captura imagética do evento. Há, assim, uma ampliação da violência pela publicização das práticas violentas. 
com a cidade e os eventos (uma vez misto de pesquisador no exterior e turista). De flâneur (BENJAMIN, 2006) a voyeur talvez, na transposição da relação sensível e direta (fenomenal?) com pessoas e objetos para uma relação mediada pela tela de poucas polegadas, uma modalidade distinta de estar no mundo se impôs.

Este texto trata da captura de imagens de um objeto amplo mas específico, a saber, as de atletas, arenas, ginásios e estádios em eventos esportivos, bem como, numa modalidade de excurso, de museus e obras de arte. Como questão, os riscos de se viver sob - e a consequente responsabilidade de exercer sobre - o domínio da câmera quando "todos", mais do que "apenas" espectadores, passamos a ser atores/autores das imagens circulantes do universo midiático-digital. Para embasar meus argumentos realizei o que chamo de micro-etnogrfia multi-situada - pois não tratou-se de um estudo de campo longo ou exaustivo ao mesmo em que estive em estádios, arenas e museus (em Madri e Paris) - entre outubro e fevereiro de 2008/09. A metodologia é fundamentada pela Antropologia Interpretativa (GEERTZ, 1989) que toma a cultura como uma trama de significados e propõe que fazer antropologia é interpretar tais significados.

O texto está organizado, para além desta introdução em três partes mais as considerações finais. Nas segunda e terceira parte descrevo os dados de campo e apresento os primeiros argumentos. $\mathrm{Na}$ quarta parte discuto a fotografia bem como o caráter performático daqueles que hoje capturam imagens em espaços públicos, e reflito sobre o individualismo contemporâneo. Nas considerações discuto o caráter ético da fotografia de/em pessoas/locais públicos e os riscos de seus usos "privados".

\section{Contexto - "micro" etnografias: Tênis, Futebol e Corrida de Touros.}

A tecnologia digital abriu possibilidades inúmeras para a produção de imagens, reorganizando o campo no qual os diversos atores sociais partilham do circuito imagético. Por um lado, com imagens realizadas a partir de celulares ou pequenas máquinas fotográficas, hoje é possível registrar a vida cotidiana em seus instantes mais inesperados. A tecnologia informacional, por outro lado, permite modos de manipulação da imagem bastante ímpares (MACHADO, 2005). Na mesma medida, a virtualidade a que as imagens são lançadas, criando um universo sem referentes, através da imaginação e capacidade técnica de artistas e técnicos, gera modos diversos de encenação, representação e interpretação destas. Importante, em ambos os casos, é a ampliação dos protagonismos, performances e produções a que os agentes têm acesso.

Acompanhando este horizonte tecnológico, sites especializados e/ ou privados (blogs, Orkut, páginas pessoais) na rede mundial de computadores organizam, informam, distribuem e reproduzem as fotos e filmes que os diversos atores/autores espalhados pelo globo enviam de suas casas. Álbuns de família, festas, encontros, equívocos, acidentes, esquetes, jogos, morte, diversão, pessoas e animais circulam num mundo cujas fronteiras são mais técnicas, econômicas e culturais do que as rígidas (geo)grafias dos mapas políticos e dos Estados Nacionais.

Ao que parece, filmes e fotos de famosos acabam por ter um apelo especial quando se trata de sua circulação e reprodução. Foram muito divulgadas as cenas de Ronaldinho chutando a bola na trave por 
três ou quatro vezes sem deixar a mesma cair, assim como o romance explícito de famosa modelo/apresentadora em praia espanhola. Entretanto, os casos são distintos: no primeiro, dúvidas quanto a sua veracidade, abrindo a discussão sobre montagem e edição; o segundo, um debate ético-moral sobre a captura de imagens: furtiva e invasiva, a visão ciclópica da câmera desnuda a privacidade, expõe as pessoas, "vigia e pune", numa ampliação multifocal do panóptico (FOUCAULT, 1997), ou seja, criando um quadro agora sinóptico (BAUMAN, 1999).

O que pretendo explorar um pouco é o sentido espetacular que um evento toma não apenas a partir da óbvia participação midiática na organização, execução e transmissão - ou publicização - de um torneio esportivo, senão o modo como aficionados pelo esporte, fãs de um ou outro jogador, além de interessados em geral tomam a imagem como base da sua relação com o vivido. Não basta estar presente, é preciso levar a presença consigo. É preciso arrastar a memória através das imagens; mas não qualquer imagem, mas sim aquela que anuncia - ou denuncia - uma prova, a de se ter estado lá. E ainda, sob outra perspectiva, talvez como pano de fundo, esteja a ideia de participar da (para depois "a") produção das imagens das quais, a profusão, os atletas e o evento são objetos.

Os atletas, para além do mundo público que os meios de comunicação e o esporte os enviam, são objetos da/de consagração privada. Seguem as micro-etnografias.

- Master Series

Treze de outubro de 2008. Depois de esperar por dez dias, chega o momento de ir ao Palácio de Cristal, em Casa de Campo, região sudoeste de Madri, para acompanhar a primeira rodada do Master Series de Madrid: torneio de tênis realizado em piso duro e quadra coberta, num centro de eventos de dimensões razoáveis. A estrutura espacial tem a seguinte ordem: chega-se por um corredor onde estão expostas imagens em tamanho ampliado dos/das principais tenistas da atualidade. Logo à esquerda, um complexo de três andares trata de abrigar as feiras e exposições que envolvem o torneio. No fundo deste complexo, no piso baixo, três quadras para aquecimento dos jogadores. Naquele mesmo corredor, o de acesso, seguindo em frente, chega-se a quadra principal. Ali tiveram lugar os jogos de simples e os principais jogos de duplas. Num canto improvisado ao qual se chega por caminho tortuoso, a quadra de duplas.

Num evento como estes a exploração da imagem é evidente. Na quadra central é possível ver as câmeras de TV em pontos estratégicos, ou mesmo inesperados, e as gruas e seus movimentos especulares. A publicidade está em todo canto, perfeitamente alinhada com os ângulos de câmera e as movimentações dos jogadores. Um telão, no intervalo dos games e sets, apresenta mais publicidade, além de ora ou outra buscar no público a imagem da torcida, da pessoa importante, da beleza, da infância... As imagens estão em profusão também nos estandes de marcas famosas: atletas, lugares, objetos... O espetáculo do tênis é quase maior do que o próprio tênis.

Nesta profusão de imagens, os aficionados, com suas câmeras de todos os tipos, não perdem a oportunidade de clicar. Foto com a foto dos atletas, foto do jogo, foto da torcida, foto do local, dos 
amigos, foto do fotógrafo... Um momento especial merece registro: separando as quadras de aquecimento e treino dos torcedores havia apenas uma mureta e alguns metros. Enquanto estive por lá, jogadores como Roger Federer, Andy Rodick, Nicolai Davidenko, entre os mais importantes do torneio, batiam bola. Amontoados na mureta, disputando espaço, fotografando freneticamente ou filmando, os aficionados do torneio produziam sua própria oferta de imagens. Atletas, treinadores, dirigentes, fotógrafos e seus amigos, além de desconhecidos entravam no arquivo digital privado dos diversos agentes. Imagens sem fim de pessoas que já tem suas imagens difundidas a profusão.

\section{- Santiago Bernabeu}

Nas duas oportunidades que tive de estar no estádio para assistir a um jogo do Real Madrid, a experiência ainda incipiente do Máster Series começou a tomar contorno. Além dos torcedores habituais, eventuais e turistas misturavam-se nas cercanias do estádio e depois em seu interior. Não havia como não perceber o desejo de registro de grande parte dos assistentes. Nas ruas, fotos dos bares, do estádio, de monumentos, das pessoas em profusão. No interior do campo, o espocar do flash quando o Real entrou em campo, nos lances de perigo, quando um atleta se aproximava da lateral...

Vale ressaltar que, em muitas ocasiões, a presença física do campo, dos jogadores e de suas movimentações é reduzida às pequenas polegadas da tela digital que oferece ao fotógrafo o simulacro da ação.
Enquanto a vida real se desenrola na disputa dos lances e na hora do gol, a co-presença é mediada pela visão ciclópica da câmera, recortando o entorno, substituindo as asperezas que objeto e horizonte infundem pelo plano chato da tela. É assim que é possível ver as luzes piscando em momentos cruciais do jogo - ou mesmo na "banalidade" de um arremesso lateral - numa ampliação dos pontos de vista da captura das imagens.

A digitalização da imagem, além disso, facilita a produção em série. Fotos sobre fotos eram, no caso do Bernabeu, insistentemente tiradas. Talvez como uma forma de prolongar o estar lá, uma prova de ter estado lá ou a busca de alguma recompensa - um sublime - aquele que possui a máquina é, mais do que torcedor ou turista, expectante de sua própria produção, voyeur de suas próprias imagens - quem sabe Narciso. Ver um jogo do Real Madrid é correr o risco de virar imagem digital mundializada, pois, na multidão, não há como se esquivar: alvos anônimos (e involuntários?) da mirada alheia (involuntária?).

\section{- Las Ventas}

Talvez o mais enigmático e espetacular evento que eu tenha apreciado em Madri foi a tourada (ou, corrida de touros, como falam os espanhóis). Algumas vezes tive oportunidade de assistir pelo canal espanhol da TV por assinatura, no Brasil, aos touros, toureiros e cavalos, lanças, espadas e movimentos de capa. Confesso um paradoxo, quiçá absurdo. Sempre carreguei comigo dois sentimentos, quais sejam, o de apreciar - no sentido de gostar - os movimentos, o perigo e a morte nas touradas. Na contra face, um sentido de barbárie na morte espetacularizada e cruel do touro - e 
por vezes do toureiro - tornava o espetáculo inquietante ${ }^{4}$. A corrida de touros, ainda assim, ou com tudo isso, a mim me parece um espetáculo bárbaro5: esteticamente belo; barbárie impassível.

Mais uma vez, as máquinas fotográficas clicavam a profusão. A entrada do touro na arena, sua força e intensidade, suas magníficas postura e ferocidade já faziam os agentes sociais, que tanto dizem sobre a própria fotografia que realizam, conforme Bourdieu $(1964)^{6}$, iniciar o registro. Os primeiros lances de capa dos toureiros antecipavam a disputa por vir. A entrada dos cavaleiros e suas lanças, a investida do touro contra o cavalo vendado enquanto o lanceiro crava sua arma no animal (marco da passagem ao segundo terço da corrida) aumentavam a tensão, tornando mais frenético o clicar das câmeras. Mais toureio. O último terço é marcado pelos homens que enfrentam o touro apenas com o corpo e suas bandeirilhas, que devem ser cravadas no costado do animal, entre o pescoço e dorso. Muitas fotos.

O último terço é finalizado com o enfrentamento derradeiro entre homem e fera. Toureiro e touro, frente a frente, encerram a "peleia" de vida e morte. Os fotógrafos profissionais se alinham, a multidão também. Todos de câmera em punho, tentando apreender os lances de capa, a tangência do touro no corpo a corpo com o toureiro... o lance mortal. Conduzido para o locus onde tudo possa ser bem visto, e devidamente registrado, o touro sofre a estocada final. A espada perfura o corpo até o coração. Sua natureza feroz faz com que o mesmo ainda lute, já de joelhos, cansado. Feliz é o aficionado/turista que conseguiu a melhor foto, do melhor ângulo da morte: substituiu a experiência direta pela imagem em miniatura e eufêmica da câmera. A tauromaquia é um espetáculo, e na sociedade do espetáculo nada escapa ao olho das câmeras.

\section{$* * *$}

Estes eventos nos ensinam aspectos fundamentais da sociedade digital sobre os quais pretendo discorrer em seguida. Apenas destaco aqui que, para além deste caráter espetacular dos eventos esportivos (mas o que será a tauromaquia?) ${ }^{7}$, um modo de tornar particular tal espetacularização se acentua através da captura privada de imagens "públicas", colhidas como uma prova, uma memória, um ganho de capital (no sentido de Bourdieu, 1982; 1998), um prêmio e/ou uma nova maneira de relação com os eventos e o mundo. Quem são os protagonistas e que performances se estabelecem são os problemas a discutir.

4 Tal ambiguidade, esta quase antinomia das sensações, tornou-se maior quando li Michel Leiris e Roland Barthes. Em ambos, pensadores importantes, formados pelo humanismo Francês do "breve séc. XX", por e com Mauss, Batalle, Grioule e Saussurre (para dizer um mínimo) pela Antropologia e a Linguística, o Existencialismo, a Fenomenologia, o Marxismo e o Estruturalismo, pela compreensão do que é o humano, mas também pelas Grandes Guerras, nenhuma palavra sobre o sofrimento do animal, nenhum tipo de piedade ou valor a vida, nada sobre o excesso ou desnecessário. Com "requintes de crueldade", apenas teses sobre a estética, a natureza, o humano, o combate, o esporte, o risco...

5 No duplo sentido que a palavra profere: fantástico e cruel.

6 Uma versão em espanhol pode ser encontrada em: < http://sociologiac.net/biblio/Bourdieu_LaFotografia.pdf >

7 Para uma reflexão sobre a tauromaquia ver Leiris (2001). 
Antes, porém, e de fato não posso me furtar a esta digressão, um pequeno excurso sobre as fotografias e filmagens realizadas nos museus de arte. Neste ponto, sem dúvida, uma complementaridade singular - uma mesma lógica ou razão (ou ideologia/cultura) - entre os modos de apreciação do esporte, dos espetáculos artísticos mais performáticos (dança, música, teatro) e as artes plásticas ajudam a traçar ainda melhor os contornos do problema.

\section{Excurso: a obra de arte na época de sua reprodutibilidade técnica ${ }^{8}$ - digital}

Chamo esta pequena digressão etnográfica de excurso mais pela fuga em relação ao objeto - do esporte para a arte (ainda que se possa pensar que o esporte seja uma forma de arte ou carregue elementos performáticos que tocam o campo artístico) - do que pelo problema colocado. Em verdade, minhas reflexões sobre a fotografia (principalmente), iniciam com minha visita aos museus, menos do que aos espaços esportivos. Tem origem no Museu do Prado, no Museu Reina Sofia em Madrid e se aprofunda em Paris, especificamente no Museu D'Orsay e no Louvre. Mais do que primeiras reflexões, indignação.
Ainda que tenha ido a Madrid para estudar a Antropologia do Esporte por lá, a primeira coisa que me moveu foi a visita aos museus. E foi assim que logo que cheguei, ainda na primeira semana, tive oportunidade de visitar o Museu do Prado. Meu objetivo: ver o quadro "Las Meninas" de Velásquez, tratado como uma revolução perspectiva (epistêmica) por Foucault na introdução de "As palavras e as Coisas" (FOUCAULT, 1992). A medida que o visitante mergulha no museu, novas descobertas: Caravaggio, Ribera, Goya, El Greco, Rubens... vão nos afetando, como é próprio à esthesis. Impossível não lembrar de Walter Benjamin.

Tendo visto em fotografias - em livros ou na internet - algumas das obras dos grandes mestres, ressoava o problema da reprodutibilidade técnica e a ausência de aura (BENJAMIN, 1994). Realmente, em meu caso específico, a experiência estética produzida na relação homem-obra de arte é incomparável ao simulacro da reprodução das imagens ${ }^{9}$. Fruir desta experiência é, ao menos para minhas capacidades, indescritível. Foi assim quando me deparei com a obra máxima de Pablo Picasso, Guernica, no Museu Reina Sofia, com o cubismo e, por certo, o surrealismo de Dalí. A cada museu ${ }^{10} \mathrm{o}$ alargamento da

8 Espero que me perdoem o abuso de utilizar o título de um texto seminal da Benjamin para discutir este breve tema, mas rendendo homenagem ao pensador alemão (ainda que o mesmo não necessite e eu não esteja a altura de tanto) foram suas ideias que provocaram as primeiras reflexões sobre o que ora exponho.

9 Não pretendo ser purista e defender a não reprodução imagética das obras. Não tenho certeza sobre a validade de uma ou outra coisa. Pois, o que aconteceria se eu jamais tivesse tido a formação que tenho e visto imagens de algumas obras de arte? Em que nível elas me tocariam? Aqui estas reflexões não têm espaço suficiente. Deixo este problema aos especialistas.

10 No caso dos museus de antropologia e arqueologia (Museu da América, por exemplo), de história, da guerra e da marinha, ou mesmo nos monumentos erguidos nas praças, outra frase de Benjamin se avivava, a saber, a de que todo monumento de cultura é também um monumento de barbárie. 
experiência estética, a descoberta do belo, do trágico, do infame, do inefável.

Os museus de Madri proíbem fotografar ou filmar as obras. Ainda assim, "desavisados" insistiam em entrar com suas máquinas e seus celulares funcionavam com alguma frequência. Pior, furtivamente, pessoas esclarecidas das restrições driblavam a vigilância dos inúmeros funcionários e sacavam suas fotos. Nestas horas, confesso, uma certa irritação tomava conta de mim: primeiro porque já há imagens suficientes destas obras (ainda que os livros de arte sejam realmente caros); segundo pela forma furtiva; terceiro porque me parecia uma traição a obra de arte, pois ali exposta, nua diante do espectador, tinha sua imagem roubada para admiração privada, tardia; por último, a esperança de encontrar na arte um caminho para o conhecimento da humanidade se desfazia na substituição da experiência estética pelo "roubo da aura". Estas eram as sensações ainda não elaboradas deste modo de estar no museu.

Mas Paris guardaria ainda mais provocações e foi no Museu D’Orsay que as coisas se tornaram mais interessantes do ponto de vista deste observador. Localizado num prédio muito bonito às margens do Senna, entre a Torre Eiffel e o Louvre, o museu é caracterizado por ter um acervo bastante importante de arte impressionista. Fases e artistas ganham sala própria: Manet,
Monet, Renoir, Van Gohg, Cézanne, Pissaro... O importante, para nosso caso, não é isto, mas o fato de, em Paris, as fotografias serem permitidas - ainda que sem o uso do flash, o que nem sempre é respeitado. Assim, já a porta do museu e em seu interior tudo é fotografado ou filmado. $\mathrm{O}$ fato que tomou destaque foi o de as pessoas, como se estivessem posando ao lado de um ídolo, esportivo ou não, eram clicadas tendo como fundo um dos autorretratos de Van Gogh. Neste instante, percebi que o museu, para grande parte dos visitantes, era um pano de fundo de sua própria passagem por Paris e pelo próprio museu.

No Louvre as coisas tomaram proporção inacreditável, evidentemente diante da Monalisa de Da Vinci. A Gioconda, único quadro protegido por um vidro e guardado a distância segura dos espectadores, era fotografada como um ícone pop. Sozinha ou acompanhada pelos turistas, a imagem mundialmente conhecida devido a sua reprodução, era, insistentemente, a companheira futura da vida privada dos agentes sociais através de sua digitalização ${ }^{11}$. Fotografar as obras de arte, mas também deixar-se fotografar diante da obra de arte são formas de apreensão do conteúdo do museu e sugerem, com certeza, reflexões sobre a fotografia e os agentes sociais na contemporaneidade.

11 A Gioconda, ao contrário de Las Meninas (grande) e Guernica (muito grande), é um quadro de dimensões pequenas. Já tive a oportunidade de ouvir sobre a decepção de pessoas com a obra devido ao seu "tamanho reduzido", à distância em que se permanece e/ou ao vidro protetor. Tal vidro, vale destacar, é uma proteção contra as possíveis agressões, a mais comum a do flash das máquinas fotográficas, que deteriora a obra de arte - não do mesmo modo, mas assim como cega o tenista na hora do saque. 
Sobre a Fotografia (e a imagem digital) reflexões sobre o campo

As discussões sobre a fotografia alcançam inúmeras áreas. A reprodutibilidade técnica benjaminiana, a "dor dos outros" sobre as fotografias de guerra - pensada por Sontag (2003; 2004), ou mesmo seu caráter mimético ou artístico. Não é este o percurso que pretendo, ainda que não se possa escapar destas asserções. O que intento neste texto é, ao modo de Bourdieu (1964), pensar o que a fotografia fala de quem é o autor/ produtor da imagem, seja como aquele que manipula a câmera ou, do outro lado, cria uma performance para ser registrada. Além destes aspectos, retomo os atletas, cujas vidas "heróicas" preenchem o álbum de fotografias do "indivíduo" moderno. Por fim, refletirei sobre os riscos de, na sociedade da imagem, tornar-se um protagonista involuntário da cena arquitetada por outros e das responsabilidades éticas aí implicadas.

Quando Bourdieu (1964) escreve sobre a fotografia tem em perspectiva, além dos sentidos constitutivos da imagem produzida, o fato de a imagem denotar algo para além dela. Significativamente, importa para o autor refletir sobre o quanto a fotografia fala do fotógrafo e de seu conjunto prático-simbólico de atuação e percepção do mundo, assim como do(s) fotografado(s), que em suas performances individuais e coletivas revelam seus gostos de classe, habitus e o espaço que ocupam no campo social. É nesta linha de reflexão que inicio estas análises.

As fotografias (as imagens em geral) tomadas dos atletas e espaços desportivos - e museus e obras de arte - sugerem um protagonismo de quem fotografa e cria as performances diante da tela. Pano de fundo, estes humanos/obras/horizontes são apropriados pelo mundo privado daqueles que criam uma composição da produção foto/ performance. Ainda que seja a presença destes que dê ao registro seu poder de aumentar o capital simbólico daquele que comprova sua presença, é a confirmação do poder dos agentes de efetivar uma posse e de, portanto, individualizar-se, radicalizando os sistemas que sustentam o individualismo contemporâneo que chamam a atenção.

Este protagonismo diante e por trás da câmera tem efeito sobre a vida coletiva de forma muito direta. Se, num primeiro aspecto, destaca-se a substituição da experiência do evento pela mediação da tela de poucas polegadas e a transformação da memória em um arquivo anexo dependente das imagens capturadas, em segundo aspecto está um modelo performático de participação no mundo feito de poses estudadas, olhares medidos, recortes discretos do espaço contínuo e aberto, além, é claro, da certeza da posse e do domínio daquilo que, uma vez registrado, vai, no processo de sociação (SIMMEL, 2006) confirmar relações e reforçar laços, ao mesmo tempo em que, através dos atributos do capital adquirido, estabelecerá hierarquias e individualizará.

A performance (TURNER, 1974; 2008), esta forma singular de ordenar o mundo e garantir a ordem aparece então, sob um caráter bastante restrito, como um rito de confirmação do poder do agente de se apropriar das coisas, de manifestar suas idiossincrasias, apontar seu pertencimento. As imagens produzidas estreitam os laços coletivos, pois a presença - transformada em co-presença pela relação simpática entre pessoas e pessoas e "objetos", pois compartilham os mesmos sentidos do mundo que habitam - que a produção/ 
performance fotográfica permite, conecta os ausentes da experiência ao vivido pelos agentes protagonistas.

Entretanto, colhido pelo poder da imagem, aquele que fotografa não perde a oportunidade de registrar o espetacular. Se o espetáculo se imiscuiu como ideologia da produção imagética - ainda que um sentido estético (no sentido do bom, belo e verdadeiro) partilhe deste ambiente incerto - suas características são dispersas. Assim, o belo ou o gesto perfeito - equilibrado, ritmado e sinuoso - dividem espaço com o grotesco, o violento, o bizarro ou o jocoso. No protagonismo que a imagem reivindica, qualquer objeto pode ser o ícone de uma posse vitoriosa.

Na mesma esteira, os atletas, cujas imagens já são profundamente exploradas através das mídias "oficiais" e preenchem as TVs - da publicidade ao telejornalismo - e as páginas da internet, tem sua privacidade invadida pela profusão de câmeras a buscar o melhor ângulo, a maior proximidade (procurando uma intimidade na co-presença) ou a pior cena. Incapazes de controlar o outro que registra, os atletas parecem ser obrigados a desenvolver, eles mesmos, um modo de performance que os proteja; resguarde dos riscos da exposição exagerada. Como ambigüidade, o fato de a razão de ser da produção deste tipo de imagem, os atletas, transformarem-se em protagonistas secundários, pois, no espírito do individualismo contemporâneo, mesmo aquele - ou aquilo - que suporia uma aura deve tornar-se objeto de posse.

Por fim, assim como os atletas, agentes sociais amontoados em torno destes "monumentos" acabam por tornarem-se presas de sua lógica. Em todos os eventos que acabo de "micro-etnografar", a multidão performática, que protagoniza e produz, é um "objeto móvel" a compor o pano de fundo da cena dos outros. O risco: ver sua imagem apropriada por um voyeurismo que nada perde e tudo registra. Se aos atletas e outros ídolos uma aura pode protegê-los dos excessos da imagem (o que em geral não têm acontecido), ao anônimo fica a impaciência de contar com o bom senso dos outros.

É neste sentido que cresce a preocupação quanto a responsabilidade daquele que, com sua câmera, captura imagens da vida alheia. Os sentidos éticos aí implicados são bastante profundos, principalmente quando vivemos no tempo em que a imagem acaba por coincidir com o objeto, como um índice que resume tudo que uma pessoa pode ser. Para nosso campo, acostumado a discutir a técnica e a tecnologia midiática em sua estrutura, os modos de recepção e os modelos de produção dos meios "tradicionais" - ou institucionais (TV, jornal, rádio, revistas, internet...) nova preocupação vêm complexificar o problema, a saber, o da produção privada de imagens públicas (ou do público, ou, ainda, do que está em público).

Retomando Bourdieu (1964), é preciso estar atento para o fato de que norma estética e norma social estão em relação. Assim, a fotografia está esteticamente sujeita ao ethos de classe, ao habitus, aos sistemas prático-simbólicos dos grupos de agentes sociais e suas funções e significações. $\mathrm{O}$ que as micro-etnografias parecem apontar é uma certeza dos agentes sobre o caráter tautológico da fotografia, que a representação da objetividade é verdadeiramente objetiva, denotando em seu caráter o aprofundamento do individualismo "burguês" (ou pequeno burguês?) e sua ânsia pelo 
acúmulo de capital e bens (materiais e simbólicos) através da captura das imagens e sua difusão.

\section{Consideração Finais - ética, imagem e Educação Física}

Enquanto estive em Madri acompanhei uma polêmica criada a partir da captura de imagens no interior da escola. Nada de atletas ou feitos heroicos, ao contrário, a reprodução do problema apontado por Rivoltella apresentado no início deste texto. Meninos de 11 e 12 anos filmaram um de seus "colegas" sendo maltratado por um pequeno grupo, numa triste forma de produção, protagonismo e performance. $\mathrm{O}$ filme" tornou-se público e as autoridades educacionais tiveram que intervir ${ }^{12}$.

Do mesmo modo, no campo profissional, há poucos anos um fotógrafo ganhou um prêmio importante por suas imagens de uma mãe salvando o filho que se afogava em um fosso. "Diante da dor dos outros" (SONTAG, 2003), a glória. Da mesma forma, anos antes, um repórter televisivo de uma emissora de Santa Catarina, fazendo uma reportagem sobre um menino que precisava de ajuda devido a uma grave doença, esforçou-se por "criar uma atmosfera de tristeza" ao insistir com a criança sobre o que aconteceria caso não recebesse a ajuda desejada ${ }^{13}$. Mas, como afirma Merleau-Ponty (1991, p. 349), "o gosto pelas notícias do cotidiano é o desejo de ver, ver é adivinhar numa ruga do rosto um mundo inteiro igual ao nosso".

Infelizmente, exemplos como estes se ampliam. As "vídeo-cacetadas" e as "pegadinhas" institucionalizaram - normalizaram? - a produção e veiculação de imagens fundamentadas no abuso, intolerância, preconceito... barbárie. Assim, no plano privado as coisas parecem andar na mesma direção. Não são poucas as imagens disponíveis na internet que tem como protagonistas pessoas não conscientes (muitas vezes realmente inconscientes, como os casos de alcoolizados ou entorpecidos) de estarem protagonizando cenas que as inferiorizam ou comprometem.

Estes eventos sugerem a ideia de que, ao indivíduo (clássico: burguês), aquilo que está disponível como objeto ou paisagem pode ser apropriado. A posse, a prova da presença ou a performance confirmam a ampliação de capitais de diferentes tipos no campo social. Por outro lado, uma vez que aquilo que foi apropriado como imagem se torna objeto de apreciação em espaços públicos - como a internet -, espaços estes que na sociedade da propriedade privada acabam por não pertencer a ninguém, ninguém mais é responsável ou moralmente implicado. $\mathrm{O}$ público torna-se o lugar de ninguém.

12 Em verdade, já havia registro na diretoria da escola de que o menino era frequentemente mal tratado pelos colegas, mas nenhuma providência havia sido tomada. As autoridades educacionais, de posse das imagens assim como as TVs, que a reproduziram em quantidade - entraram em ação para apuração de responsáveis. Os pais do menino mal tratado entraram com ação na justiça contra a escola e o Estado. O fato ainda repercute e está na justiça.

13 Este caso, de pouca repercussão, foi uma das mais repugnantes reportagens que já vi, pois encerrava com o menino chorando, dizendo que morreria caso não encontrasse ajuda para o tratamento. 
Volto a Merleau-Ponty (1991, p. 349) para acrescentar o perigo da anomia na profusão de imagens, pois:

(...) ver é também aprender que os prazeres, que as dores sem limites que se acumulam em nós não passam de uma pobre careta para o espectador estranho. Pode-se ver tudo, e viver depois de tudo isto. Ver é essa estranha maneira de tornar-se presente mantendo as distâncias, e, sem participar, transformar os outros em coisas visíveis. Aquele que vê se julga invisível: seus atos permanecem para ele na companhia lisonjeira de suas intenções, e ele priva os outros desse álibi, reduzindo-os a algumas palavras, a alguns gestos. $\mathrm{O}$ espectador é sádico.

Por fim, os aspectos aqui levantados, que envolvem a produção de imagens de modo geral - e por certo um modo de ver - e as que têm como protagonistas atletas e espaços públicos esportivos, performances e protagonismos de diferentes tipos, confirmam a pertinência dos esforços realizados no campo da Educação Física, por diferentes grupos de pesquisa sobre mídia, além de professores de diferentes instituições, no sentido de se compreender a mídia em suas diferentes formas de manifestação e as implicações éticas e morais para a formação do "sujeito esclarecido".

\section{REFERÊNCIAS}

ADORNO, T \& HORKHEIMER M. Dialética do Esclarecimento. Rio de Janeiro/RJ: Jorge Zahar, 1985.

BAUMAN, Z. Globalização: as consequências humanas. São Paulo: Jorge Zahar, 1999. BENJAMIN, Walter. "A Obra de Arte na Era de Sua Reprodutibilidade Técnica". In: Magia e Técnica, Arte e Política: ensaios sobre literatura e história da cultura. São Paulo: Brasiliense, 1994. - (Obras Escolhidas). . "O Flâneur". In: Passagens. Belo Horizonte: Editora UFMG; São Paulo: Imprensa Oficial do estado de São Paulo, 2006.

BIANCHI, Paula. Formação Continuada e Mídia-Educação (Física): Ações Colaborativas na Rede Municipal de Florianópolis/SC. Programa de PósGraduação em Educação Física da UFSC, 2009. - Dissertação de Mestrado. BITENCOURT, Fernando Gonçalves. "Metáforas do Esporte - Imagens e Narrativas de Guerra: o uso da linguagem esportiva na cobertura jornalística da guerra entre os Estados Unidos e Iraque". Revista Brasileira de Ciências do Esporte. Campinas, v. 26, n. 2, p. 09-20, janeiro/2005a.

BITENCOURT, Fernando Gonçalves, et al. "Ritual Olímpico e os Mitos da Modernidade: Implicações Midiáticas na Dialética Universal/Local". Revista Pensar a Prática Goiânia, v. 8, n. 1, p. 21-36, jan./jun 2005b.

BOURDIEU, Pierre et. al. Un art moyen. Paris: Minuit, 1964.

. A economia das trocas simbólicas. São Paulo: Perspectiva, 1982.

. O Poder Simbólico. Rio de Janeiro /RJ: Bertrand Brasil, 1998.

. El Sentido Práctico. Buenos Aires: Siglo XXI Editores Argentina, 2007.

DEBORD, Guy. A Sociedade do espetáculo: comentários sobre a sociedade do espetáculo. Rio de Janeiro: Contraponto, 1997.

FOUCAULT, Michel. As Palavras e as

Coisas. São Paulo: Martins Fontes, 1992. 

1997.

. Vigiar e Punir. Petrópolis: Vozes,

LEIRIS, Michel. Espelho da Tauromaquia.

São Paulo: Cosac \& Naify, 2001.

MACHADO, Arlindo. "A Fotografia Sob o Impacto da Eletrônica". In: SAMAIN, Etienne. O Fotográfico. São Paulo: Hucitec, 2005.

MENDES, Diego S. Luz, Câmera e Pesquisa-

Ação: a inserção da Mídia-Educação na formação contínua de professores de Educação Física. Programa de Pós-Graduação em Educação Física da UFSC, 2008a. - Dissertação de Mestrado. . "Desvendando a janela de vidro: relato de uma experiência escolar de mídia-educação e Educação Física". Congresso Sulbrasileiro de Ciências do Esporte, 4, Anais... Faxinal do Céu

- Pinhão/PR: CBCE, setembro/2008b. MERLEAU-PONTY, Maurice. "Sobre as Notícias do Cotidiano". In: Signos. São Paulo, Martins Fontes: 1991.
OLIVEIRA, Márcio Romeu R. "Cultura de movimento e fotografia na Educação Física Escolar". Revista Movimento, v. 11, n. 2, maio/ago., 2005a.

- "Luzes, câmera e ação: uma idéia na cabeça e a câmera na mão!!!" Revista Motrivivência, n. 20/21 (especial 15 anos), p. 221-228, 2003 (circulação em jan./2005b).

SIMMEL, Georg. Questões Fundamentais de Sociologia: indivíduo e sociedade. Rio de Janeiro: Jorge Zahar, 2006.

SONTAG, Susan. Diante da Dor dos Outros. São Paulo: Companhia das Letras, 2003. . Sobre a Fotografia. São Paulo: Companhia das Letras, 2004.

TURNER, Victor. O Processo Ritual: estrutura e anti-estrutura. Petrópolis: Vozes, 1974.

. Dramas, Campos e Metáforas: ação simbólica na sociedade humana. Niterói: EdUFF, 2008.

PHOTOGRAPHY IN THE DIGITAL ERA: production, protagonism and performance problems to Physical Education/Science of Sports

\begin{abstract}
This text, the result of observations arising from "micro-ethnographies" performed during a Doctorate's training in Madrid, reflects about photography, taken by different social agents, of athletes and sportive areas in the digital era. Considering the wealth of images and easiness of dissemination through Internet, it questions the moral-ethical implications of taking these images and the meanings of production, protagonism and performance. I suggest there is 'class taste' and 'habitus' guiding these practices. The ownership of someone else's imagine (of idols and anonymous) and the exacerbation of individualism characterize this' ethos', which danger lies in the private use and in the inconsequential advertising of other people's lives.
\end{abstract}

Keywords: Physical Education/ Science of Sports; Media; Photography; Ethics 
V. $26, n^{\circ} 43$, dezembro/2014

FOTOGRAFÍA EN LA ERA DIGITAL: producción, protagonismo y performance - problemas para la Educación Física/Ciencias del Deporte

\section{RESUMEN}

Este texto, fruto de las observaciones oriundas de "micro" etnografías realizadas durante la práctica de doctorado en Madrid, refleja sobre la fotografía, toma por agentes sociales distinguidos de deportistas y espacios de deportivos en la era digital. Considerando la profusión de imágenes y la facilidad de difusión por Internet, cuestiona implicaciones ético-morales de la captura de estas y los sentidos de la producción, protagonismo y performances. Sugiero haber 'gusto de class' y 'habitus' a orientar estas prácticas. La apropiación de la imagen ajena (de ídolos y anónimos) y la exacerbación del individualismo caracterizan este 'ethos', cuyo peligro reside en el uso privado y en la publicación inconsecuente de la vida ajena.

Palabras clave: Educación Física/Ciencias del Deporte; Media; Fotografía; Ética

Recebido em: abril/2014 Aprovado em: outubro/2014 